\title{
Facile Preparation, Characterization, and Highly Effective Microwave Absorption Performance of $\mathrm{CNTs} / \mathrm{Fe}_{3} \mathrm{O}_{4} /$ PANI Nanocomposites
}

\author{
Deqing Zhang, ${ }^{1}$ Xiuying Yang, ${ }^{1}$ Junye Cheng, ${ }^{2}$ Mingming Lu, ${ }^{3}$ \\ Bin Zhao, ${ }^{4}$ and Maosheng $\mathrm{Cao}^{3}$ \\ ${ }^{1}$ Key Laboratory of Fine Chemicals of College of Heilongjiang Province, Qiqihar University, Qiqihar 161006, China \\ ${ }^{2}$ School of Energy and Power Engineering, University of Shanghai for Science and Technology, Shanghai 200093, China \\ ${ }^{3}$ School of Materials Science and Engineering, Beijing Institute of Technology, Beijing 100081, China \\ ${ }^{4}$ School of Materials Science and Engineering, University of Shanghai for Science and Technology, Shanghai 200093, China \\ Correspondence should be addressed to Deqing Zhang; zhdqing@163.com
}

Received 5 September 2013; Accepted 3 October 2013

Academic Editor: John Zhanhu Guo

Copyright (C) 2013 Deqing Zhang et al. This is an open access article distributed under the Creative Commons Attribution License, which permits unrestricted use, distribution, and reproduction in any medium, provided the original work is properly cited.

\begin{abstract}
A facile method has been developed to synthesize light-weight $\mathrm{CNTs} / \mathrm{Fe}_{3} \mathrm{O}_{4} / \mathrm{PANI}$ nanocomposites. The formation route was proposed as the coprecipitation of $\mathrm{Fe}^{2+}$ and $\mathrm{Fe}^{3+}$ and an additional process of in situ polymerization of aniline monomer. The structure and morphology of $\mathrm{CNTs} / \mathrm{Fe}_{3} \mathrm{O}_{4} / \mathrm{PANI}$ were characterized by transmission electron microscopy (TEM), X-ray photoelectron spectroscopy (XPS), and Fourier transform infrared (FTIR) spectroscopy. The TEM investigation shows that the $\mathrm{CNTs} / \mathrm{Fe}_{3} \mathrm{O}_{4} /$ PANI nanocomposites exhibit less intertwined structure and that many more $\mathrm{Fe}_{3} \mathrm{O}_{4}$ particles are attached homogeneously on the surface of CNTs, indicating that PANI can indeed help CNTs to disperse in isolated form. The waveabsorbing properties were investigated in a frequency of 2-18 GHz. The results show that the $\mathrm{CNTs} / \mathrm{Fe}_{3} \mathrm{O}_{4} / \mathrm{PANI}$ nanocomposites exhibit a super absorbing behavior and possess a maximum reflection loss of $-48 \mathrm{~dB}$ at $12.9 \mathrm{GHz}$, and the bandwidth below $-20 \mathrm{~dB}$ is more than $5 \mathrm{GHz}$. More importantly, the absorption peak frequency ranges of the CNTs/ $\mathrm{Fe}_{3} \mathrm{O}_{4} / \mathrm{PANI}$ composites can be tuned easily by changing the wax weight ratio and thickness of $\mathrm{CNTs} / \mathrm{Fe}_{3} \mathrm{O}_{4} / \mathrm{PANI}$ paraffin wax matrix.
\end{abstract}

\section{Introduction}

With the rapid increase in the use of telecommunications, digital systems, and fast processors, electromagnetic interference (EMI) has become a great concern. A microwave absorber is a kind of functional material that can absorb electromagnetic (EM) waves effectively and convert EM energy into thermal energy or make EM waves dissipate by interference [1]. Over the past decade, a variety of materials used as microwave absorbers have been extensively studied with increasing demand for innovative EMI shielding [26]. Among the pursued materials, carbon nanotubes (CNTs) have attracted extensive development effort for their unique structural, high electrical conductivity, outstanding chemical stability, and mechanical properties [7-9]. However, excellent microwave absorption properties cannot be obtained for unmodified CNTs because their magnetic loss is so small [10]. To optimize the performances of CNTs as microwave absorbers, it is necessary to modify CNTs by decorating other nanomaterials, which are expected to exhibit ideal electromagnetic absorption properties $[11,12]$.

In recent years, more and more research has been conducted in decorating CNTs with iron oxide and preparing magnetic nanoparticles due to their unique magnetic features, low cost, and strong absorption characteristics [13, 14]. Various chemistry-based processing routes have been developed to synthesize iron oxide/CNTs nanocomposite. Correa-Duarte et al. [15] coated CNTs with iron oxide nanoparticles (magnetite/maghemite) via a layer by layer assembly technique and aligned CNTs chains in relatively small external magnetic fields. Youn et al. [16] decorated 
single walled carbon nanotubes (SWNTs) with iron oxide nanoparticles along the nanotube via a magnetoevaporation method. In addition, Jia et al. [17] initiated the selfassembly of magnetite particles along multiwalled CNTs via a hydrothermal process. However, there are still disadvantages in most of these processes, which mainly include the points as follows: (1) $\mathrm{Fe}_{3} \mathrm{O}_{4}$ materials usually suffer from ease of oxidation and relatively narrow absorption frequency range, which hamper their applications, and (2) the dispersion of the nanocomposite is poor, and the orientation of the deposition of $\mathrm{Fe}_{3} \mathrm{O}_{4}$ nanoparticles on the surfaces of CNTs is difficult to control.

In order to solve these problems, here in this report the $\mathrm{CNTs} / \mathrm{Fe}_{3} \mathrm{O}_{4} / \mathrm{PANI}$ nanocomposites were fabricated by the coprecipitation of $\mathrm{Fe}^{2+}$ and $\mathrm{Fe}^{3+}$ and an additional process of in situ polymerization of aniline monomer. Polyaniline (PANI), polymerized from the inexpensive aniline monomer, was considered as an ideal matrix or a second phase incorporated with CNTs for its unique electromagnetic shielding and attenuation [18]. Furthermore, the facile preparation, structure characterization, and wave absorption performance of $\mathrm{CNTs} / \mathrm{Fe}_{3} \mathrm{O}_{4} / \mathrm{PANI}$ nanocomposite materials were investigated. The effects of several factors on wave absorption properties of $\mathrm{CNTs} / \mathrm{Fe}_{3} \mathrm{O}_{4} / \mathrm{PANI}$ nanocomposites were discussed.

\section{Experimental Section}

2.1. The Pretreatment of MWCNTs. MWCNTs (purity $>95 \mathrm{wt} \%$, 20-30 $\mathrm{nm}$ outer diameter, 10-30 $\mu \mathrm{m}$ length) were purchased from Chengdu Organic Chemicals Co. Ltd, Chinese Academy of Science. The as-supplied MWCNTs were processed in concentrated sulfuric acid with vigorous ultrasonic vibration treatment $(30 \mathrm{~W}, 40 \mathrm{kHz})$ for $2 \mathrm{~h}$ at $50^{\circ} \mathrm{C}$. After that, the mixture was followed by vacuum filtration, and washed with deionized water until the $\mathrm{pH}$ value of washing solution is neutral. Then, the filtered solid was dried under vacuum for $24 \mathrm{~h}$ at $60^{\circ} \mathrm{C}$, obtaining acidulated MWCNTs.

2.2. The Preparation of $\mathrm{CNTs} / \mathrm{Fe}_{3} \mathrm{O}_{4} / \mathrm{PANI}$ Nanocomposite Materials. $\mathrm{NH}_{2} \mathrm{Fe}\left(\mathrm{SO}_{4}\right)_{2} \cdot 6 \mathrm{H}_{2} \mathrm{O}$ was employed as the precursor for the synthesis of $\mathrm{Fe}_{3} \mathrm{O}_{4}$ magnetic nanoparticles. $\mathrm{NH}_{2} \mathrm{Fe}\left(\mathrm{SO}_{4}\right)_{2} \cdot 6 \mathrm{H}_{2} \mathrm{O}(1.0 \mathrm{~g})$ was dissolved first in a mixture of deionized water $(15 \mathrm{~mL})$ and hydrazine hydrate solution $(5 \mathrm{~mL})$ with a volume ratio of $3: 1$ under constant stirring. Then, $0.4 \mathrm{~g}$ of acidulated MWCNTs was added into the above solution. After 30 min ultrasonic vibration, a black suspension with homogeneously dispersed MWCNTs was obtained. Ammonia water $(1.0 \mathrm{~mol} / \mathrm{L})$ was then added until the $\mathrm{pH}$ value of the solution was 11.0. The stable aqueous suspension was subsequently long-drawn reflux condensed in a thermostatic water bath at the temperature of $100^{\circ} \mathrm{C}$. After approximately $2 \mathrm{~h}$, the products were cooled to room temperature. Meanwhile, the obtained products were quickly redispersed in $30 \mathrm{~mL}$ deionized water. Benzenesulfonic acid with certain concentration $(1.5 \mathrm{~mol} / \mathrm{L})$ and aniline $(0.2 \mathrm{~g})$ was subsequently added. Until homogenous suspension was achieved, ammonium persulfate (APS) aqueous solution
( $0.2 \mathrm{~g}$ of APS in $20 \mathrm{~mL}$ of deionized water) was dropwise added to the suspension. The polymerization process was applied in an ice bath for $6 \mathrm{~h}$ under vigorous stirring. The resulting precipitations were washed with deionized water and absolute ethanol several times to remove the remaining impurities. In the next step, the as-prepared product was dried under vacuum for $24 \mathrm{~h}$ at $60^{\circ} \mathrm{C}$.

\section{Characterization}

The morphology and size distribution of the samples were investigated by means of transmission electron microscopy (TEM, JEM-2010F, Germany). The ferroferric oxide nanoparticle in $\mathrm{CNTs} / \mathrm{Fe}_{3} \mathrm{O}_{4} / \mathrm{PANI}$ nanocomposites was examined specially by X-ray photoelectron spectroscopy (XPS). Fourier transform infrared spectroscopy (FTIR) was carried out on a Nicolet 8700 FTIR system. The reflection loss was measured with an Anritsu 37269D vector network analyzer in the 2-18 GHz range for which the samples were prepared by uniformly mixing the $\mathrm{CNTs} / \mathrm{Fe}_{3} \mathrm{O}_{4} / \mathrm{PANI}$ nanocomposites in a paraffin matrix which is pressed in a cylindrical shape with thickness of $2.00 \mathrm{~mm}$.

\section{Results and Discussion}

4.1. TEM Images of CNTs $/ \mathrm{Fe}_{3} \mathrm{O}_{4} / \mathrm{PANI}$ and $\mathrm{CNTS} / \mathrm{Fe}_{3} \mathrm{O}_{4}$. The typical morphology of the as-prepared $\mathrm{CNTs} / \mathrm{Fe}_{3} \mathrm{O}_{4} / \mathrm{PANI}$ is shown in Figure 1(a). As a comparison, CNTs $/ \mathrm{Fe}_{3} \mathrm{O}_{4}$ samples prepared without PANI are presented in Figure 1(b), demonstrating smaller average diameter observed in the latter because of the nonexistence of PANI coating. What is more, in Figure 1(b) samples of $\mathrm{CNTs} / \mathrm{Fe}_{3} \mathrm{O}_{4}$ prepared without PANI seem to be a bundle that CNTs are intertwined with each other and that $\mathrm{Fe}_{3} \mathrm{O}_{4}$ magnetic nanoparticles aggregate closely. However, the samples prepared in the presence of PANI (shown in Figure 1(a)) exhibit less entangled structure due to the wrapping of PANI. In other words, the use of PANI as a dispersant in the preparation process of $\mathrm{CNTs} / \mathrm{Fe}_{3} \mathrm{O}_{4}$ can indeed help CNTs to disperse as individuals or smaller bundles. On the other hand, the TEM image of $\mathrm{CNTs} / \mathrm{Fe}_{3} \mathrm{O}_{4} / \mathrm{PANI}$ also indicates that a large number of $\mathrm{Fe}_{3} \mathrm{O}_{4}$ nanoparticles adhered on the CNTs are distributed relatively homogeneously and with tiny diameters in the range of 3-5 nm; promising $\mathrm{CNTs} / \mathrm{Fe}_{3} \mathrm{O}_{4} / \mathrm{PANI}$ nanocomposites prepared with PANI may have higher magnetic properties and absorption characteristics. Furthermore, it is noticeable that the interaction between $\mathrm{Fe}_{3} \mathrm{O}_{4}$ nanoparticles and CNTs was strong in the presence of PANI, as few $\mathrm{Fe}_{3} \mathrm{O}_{4}$ nanoparticles were observed on the copper grids suffering from repeated washing and sonicating in the process.

4.2. XPS Analysis of $\mathrm{CNTs} / \mathrm{Fe}_{3} \mathrm{O}_{4} / \mathrm{PANI}$. XPS has often been used for the surface characterization of various materials, and unambiguous results are readily obtained when the various surface components each contain unique elemental markers. Here, in order to further analyse the $\mathrm{CNTs} / \mathrm{Fe}_{3} \mathrm{O}_{4} / \mathrm{PANI}$ products, XPS was measured to understand the composition of the magnetic nanoparticles surface in Figure 2. Figure 2(a) 


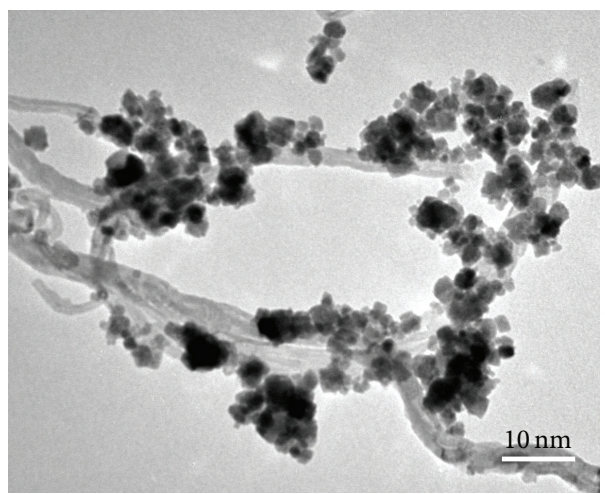

(a)

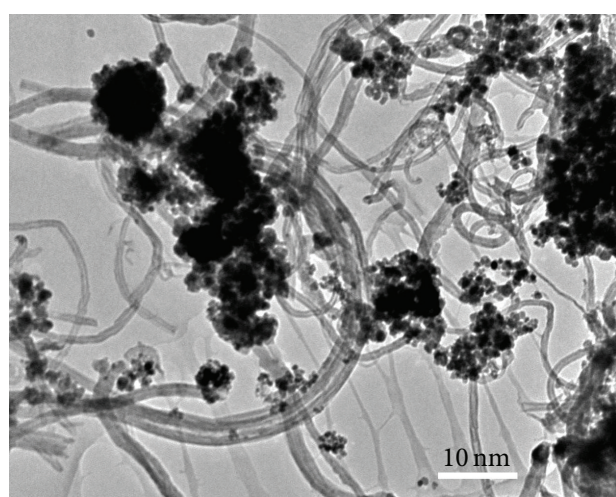

(b)

Figure 1: (a) TEM image of the as-prepared CNTs/ $\mathrm{Fe}_{3} \mathrm{O}_{4} / \mathrm{PANI}$; (b) TEM image of CNTs/ $\mathrm{Fe}_{3} \mathrm{O}_{4}$.

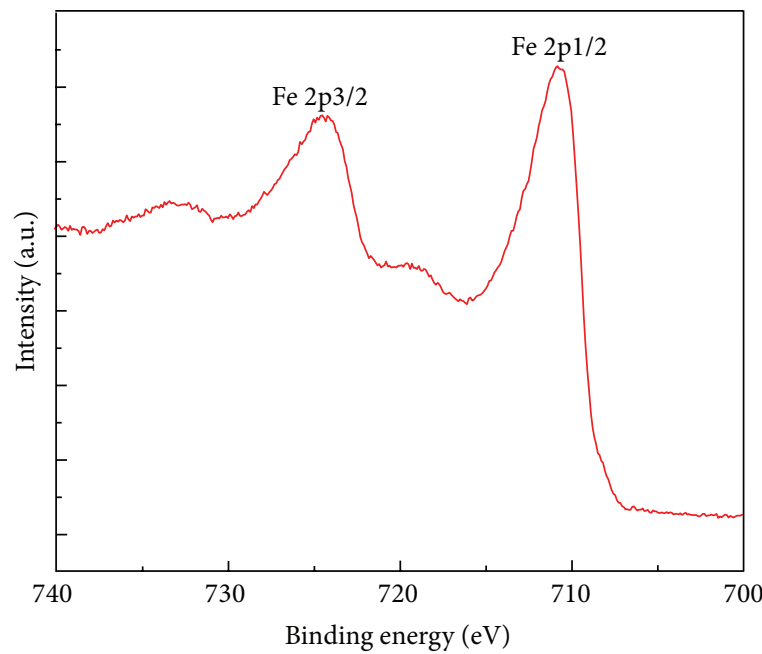

(a)

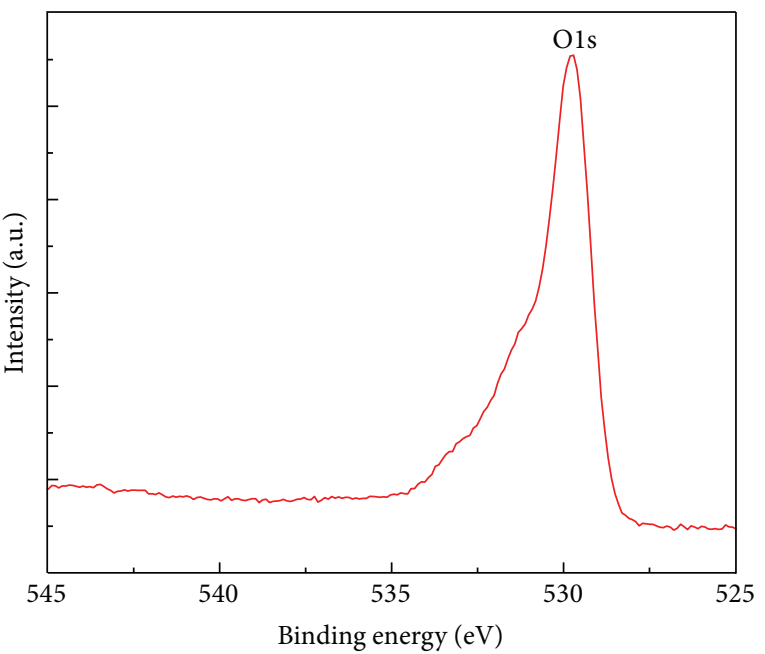

(b)

FIGURE 2: (a) XPS signal from Fe in $\mathrm{Fe}_{3} \mathrm{O}_{4}$ magnetic nanoparticles; (b) XPS signal from oxygen in $\mathrm{Fe}_{3} \mathrm{O}_{4}$ magnetic nanoparticles.

shows the XPS signals of the Fe $2 \mathrm{p}$ region. Two peaks of $\mathrm{Fe}$ $2 \mathrm{p} 1 / 2$ at $710.6 \mathrm{eV}$ and $\mathrm{Fe} 2 \mathrm{p} 3 / 2$ at $723.9 \mathrm{eV}$ were observed, respectively. The $\mathrm{O}$ 1s spectrum in Figure 2(b) consisted of a mean peak originating from the oxygen in $\mathrm{Fe}_{3} \mathrm{O}_{4}$ (at $529.7 \mathrm{eV}$ ) and a shoulder centered at $531.3 \mathrm{eV}$, which has been ascribed to surface traps [19]. The Fe/O ratio was estimated as 0.74 with curve resolution analysis, which matches well with the stoichiometric ratio of $\mathrm{Fe}_{3} \mathrm{O}_{4}(0.75)$. The data are also consistent with the values reported for $\mathrm{Fe}_{3} \mathrm{O}_{4}$ in the literature [20-22]. Therefore, XPS results also prove the composition of the products.

4.3. FTIR Analysis of $\mathrm{CNTS} / \mathrm{Fe}_{3} \mathrm{O}_{4} / \mathrm{PANI}$. FTIR spectra of samples were recorded at room temperature, which are shown in Figure 3. Figure 3(a) shows the results of neat PANI. Figure 3(b) shows the $\mathrm{CNTs} / \mathrm{Fe}_{3} \mathrm{O}_{4} / \mathrm{PANI}$ samples prepared in the presence of PANI. For the CNTs/Fe $\mathrm{O}_{4} / \mathrm{PANI}$ nanocomposite, the peaks appearing at 3268, 1587, 1496, 1310, 1165 , and $832 \mathrm{~cm}^{-1}$ indicate the formation of PANI. The peaks at 1587 and $1496 \mathrm{~cm}^{-1}$ are assigned to the stretching vibration of $\mathrm{C}=\mathrm{N}$ in quinoid ring and $\mathrm{C}=\mathrm{C}$ in benzenoid ring [23]. The peak at $3268 \mathrm{~cm}^{-1}$ is attributed to the $\mathrm{N}-\mathrm{H}$ stretching vibration in PANI [23]. However, compared with the spectra of the PANI, the peaks of the $\mathrm{CNTs} / \mathrm{Fe}_{3} \mathrm{O}_{4} / \mathrm{PANI}$ nanocomposites shifted slightly in the direction of low wavenumber. This may be attributed to the interaction between the CNTs and the PANI [24]. What is more, owing to lower concentrations of PANI in CNTs/ $\mathrm{Fe}_{3} \mathrm{O}_{4} / \mathrm{PANI}$ samples and the introduction of the CNTs, the intensity of the peaks of the $\mathrm{CNTs} / \mathrm{Fe}_{3} \mathrm{O}_{4} / \mathrm{PANI}$ nanocomposite decreased.

4.4. Reaction Mechanism Explanation of As-Prepared $\mathrm{CNTs} / \mathrm{Fe}_{3} \mathrm{O}_{4} / \mathrm{PANI}$. In view of the unique and facile synthesis process, the reaction mechanism of $\mathrm{CNTs} / \mathrm{Fe}_{3} \mathrm{O}_{4} / \mathrm{PANI}$ nanocomposites is schematically illustrated in Figure 4 . It is well known that treating the CNTs with sulfuric acid could create considerable functional groups such as carboxyl or carbonyl on the outside surface of CNTs which became negatively charged. The large number of the carboxylic acid or carbonyl groups on the outside of the CNTs could catch 


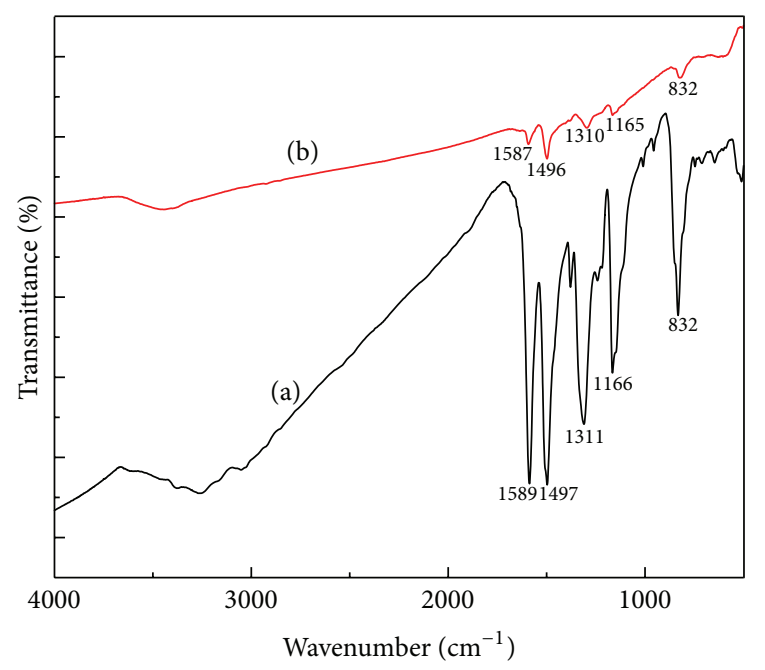

FIgURE 3: FTIR spectra of the (a) PANI and (b) CNTs/Fe $\mathrm{O}_{4} / \mathrm{PANI}$.

and strongly bond with $\mathrm{Fe}^{2+}$ ions in $\mathrm{NH}_{2} \mathrm{Fe}\left(\mathrm{SO}_{4}\right)_{2} \cdot 6 \mathrm{H}_{2} \mathrm{O}$ solution through electrostatic attraction. Then, after the addition of $\mathrm{N}_{2} \mathrm{H}_{4}$ solution, many primary $\mathrm{Fe}^{2+}$ ions further interacted with $\mathrm{N}_{2} \mathrm{H}_{4}$ into $\mathrm{Fe}^{3+}$ ions under alkaline condition $(\mathrm{PH}=11-13)$. In the following long-drawn reflux process, large quantities of obtained $\mathrm{Fe}^{3+}$ ions and incipient unreacted $\mathrm{Fe}^{2+}$ ions went through intensive coprecipitation reaction. Finally the $\mathrm{Fe}_{3} \mathrm{O}_{4}$ magnetic nanoparticles formed and adhered on the surface of CNTs driven by the minimization of surface energy. The $\mathrm{OH}^{-}$ions play an important role in the formation of $\mathrm{Fe}_{3} \mathrm{O}_{4}$ magnetic nanoparticles. When $\mathrm{NH}_{3} \cdot \mathrm{H}_{2} \mathrm{O}$ creating $\mathrm{OH}^{-}$ions took place in the aqueous solution, the $\mathrm{OH}^{-}$, as an inorganic ligand, would first interact with $\mathrm{Fe}^{2+}$ forming $\mathrm{Fe}(\mathrm{OH})_{2}$. This will promote the further interaction between $\mathrm{Fe}(\mathrm{OH})_{2}$ and $\mathrm{N}_{2} \mathrm{H}_{4}$ so that the obtained $\mathrm{Fe}(\mathrm{OH})_{3}$ could combine with $\mathrm{Fe}(\mathrm{OH})_{2}$ under the favourable $\mathrm{OH}^{-}$condition. The reaction processes can be briefly described as

$$
\begin{gathered}
\mathrm{Fe}^{2+}+2(\mathrm{OH})^{-} \longrightarrow \mathrm{Fe}(\mathrm{OH})_{2} \\
\mathrm{Fe}(\mathrm{OH})_{2}+\mathrm{N}_{2} \mathrm{H}_{4}+4 \mathrm{H}_{2} \mathrm{O} \longrightarrow \mathrm{Fe}(\mathrm{OH})_{3}+2 \mathrm{NH}_{4} \mathrm{OH} \\
2 \mathrm{Fe}(\mathrm{OH})_{3}+\mathrm{Fe}(\mathrm{OH})_{2}
\end{gathered}
$$

Then, the in situ polymerization happened in the quick process, which seemingly improved the distribution of $\mathrm{Fe}_{3} \mathrm{O}_{4}$ magnetic nanoparticles, getting the fine $\mathrm{CNTs} / \mathrm{Fe}_{3} \mathrm{O}_{4} / \mathrm{PANI}$ nanocomposites (Figure 1(a)).

4.5. Microwave Absorption Theory. For the microwave absorption properties, the samples were first disposed by mixing with paraffin wax in an ether solution, followed by evaporating the solvent. The dried samples were collected and compressed into a toroidal shape. The reflection loss (RL) values of $\mathrm{CNTs} / \mathrm{Fe}_{3} \mathrm{O}_{4} / \mathrm{PANI}$ and $\mathrm{CNTs} / \mathrm{Fe}_{3} \mathrm{O}_{4}$ composites were calculated using the relative complex permittivity and permeability at a given frequency and thickness layer according to the transmit line theory, which is summarized as the following equations [25]:

$$
\begin{gathered}
Z_{\text {in }}=\sqrt{\frac{\mu_{r}}{\varepsilon_{r}}} \tanh \left[-j \frac{2 \pi}{c} \sqrt{\mu_{r} \varepsilon_{r}} f d\right], \\
\mathrm{RL}(\mathrm{dB})=-20 \log _{10} \frac{\left|Z_{\text {in }}-1\right|}{\left|Z_{\text {in }}+1\right|},
\end{gathered}
$$

where $\varepsilon_{r}$ and $\mu_{r}$ are the relative complex permittivity and permeability of the composite medium, respectively, $f$ is the frequency of the microwave in free space, $c$ is the velocity of light, $d$ is the absorber thickness, and $Z_{\text {in }}$ is the input impedance of the absorber.

4.6. The Comparison of Microwave Absorption Properties between $\mathrm{CNTs} / \mathrm{Fe}_{3} \mathrm{O}_{4} / \mathrm{PANI}$ and $\mathrm{CNTs} / \mathrm{Fe}_{3} \mathrm{O}_{4}$. Figure 5 shows the reflection loss characteristics curve of the $\mathrm{CNTs} / \mathrm{Fe}_{3} \mathrm{O}_{4} / \mathrm{PANI}$ and $\mathrm{CNTs} / \mathrm{Fe}_{3} \mathrm{O}_{4}$ samples under the same paraffin wax weight ratio $(20 \mathrm{wt} \%)$ condition, which was calculated by the previous equations (4) and (5). In this calculation, $d$ was considered to be $2 \mathrm{~mm}$. The samples prepared with PANI exhibit the largest reflection loss of $-48 \mathrm{~dB}$ at $12.9 \mathrm{GHz}$, which is in an interval width of $5.2 \mathrm{GHz}$ with losses all below $-20 \mathrm{~dB}$. The samples prepared without PANI have a maximum reflection loss of $-44 \mathrm{~dB}$ at $13.1 \mathrm{GHz}$ with about $5.5 \mathrm{GHz}$ bandwidth below $-20 \mathrm{~dB}$. In the comparison of $\mathrm{CNTs} / \mathrm{Fe}_{3} \mathrm{O}_{4} / \mathrm{PANI}$ with $\mathrm{CNTs} / \mathrm{Fe}_{3} \mathrm{O}_{4}$, the CNTs/ $/ \mathrm{Fe}_{3} \mathrm{O}_{4} / \mathrm{PANI}$ samples with PANI have the largest reflection loss of $-48 \mathrm{~dB}$, which is higher than that of samples without PANI, while the frequency region (below $-20 \mathrm{~dB}$ ) between the two is approximated. These results indicate that the samples prepared with PANI have relative better absorption properties than those of samples without PANI. Normally, microwave absorption depends on the impedance match conditions of the interfaces between the fillers and air [26]. Thus, the existence of PANI coatings with a different electrical conductivity and dielectric properties could change the impedance between CNTs and air, leading to $\mathrm{CNTs} / \mathrm{Fe}_{3} \mathrm{O}_{4}$ microwave absorption performance superior to $\mathrm{CNTs} / \mathrm{Fe}_{3} \mathrm{O}_{4} / \mathrm{PANI}$ composites. However, the results display the deviation which can be attributed to the dispersion of the $\mathrm{CNTs} / \mathrm{Fe}_{3} \mathrm{O}_{4} / \mathrm{PANI}$ samples, which is better than that of the samples prepared without PANI. It is further proved that the dispersion of the $\mathrm{CNTs} / \mathrm{Fe}_{3} \mathrm{O}_{4}$ nanocomposites is poor, and the orientation of the deposition of $\mathrm{Fe}_{3} \mathrm{O}_{4}$ nanoparticles on the surfaces of CNTs is difficult to control. Also, it is worth noting that the reflection loss results of both are much more effective than those of many naked CNT composites in previous reports $[27,28]$.

4.7. The Effects of Several Factors on Wave Absorption Properties of $\mathrm{CNTs} / \mathrm{Fe}_{3} \mathrm{O}_{4} / \mathrm{PANI}$. Figure 6(a) presents the experimental results of the reflection loss versus frequency for $\mathrm{CNTs} / \mathrm{Fe}_{3} \mathrm{O}_{4} /$ PANI wax composites with the increase of paraffin wax weight ratio from 10 to $25 \mathrm{wt} \%$ in the range of 2-18 GHz. The CNTs/ $\mathrm{Fe}_{3} \mathrm{O}_{4} / \mathrm{PANI}$ composites with a paraffin wax weight ratio of $10 \mathrm{wt} \%$ show weak wave-absorbing ability, 


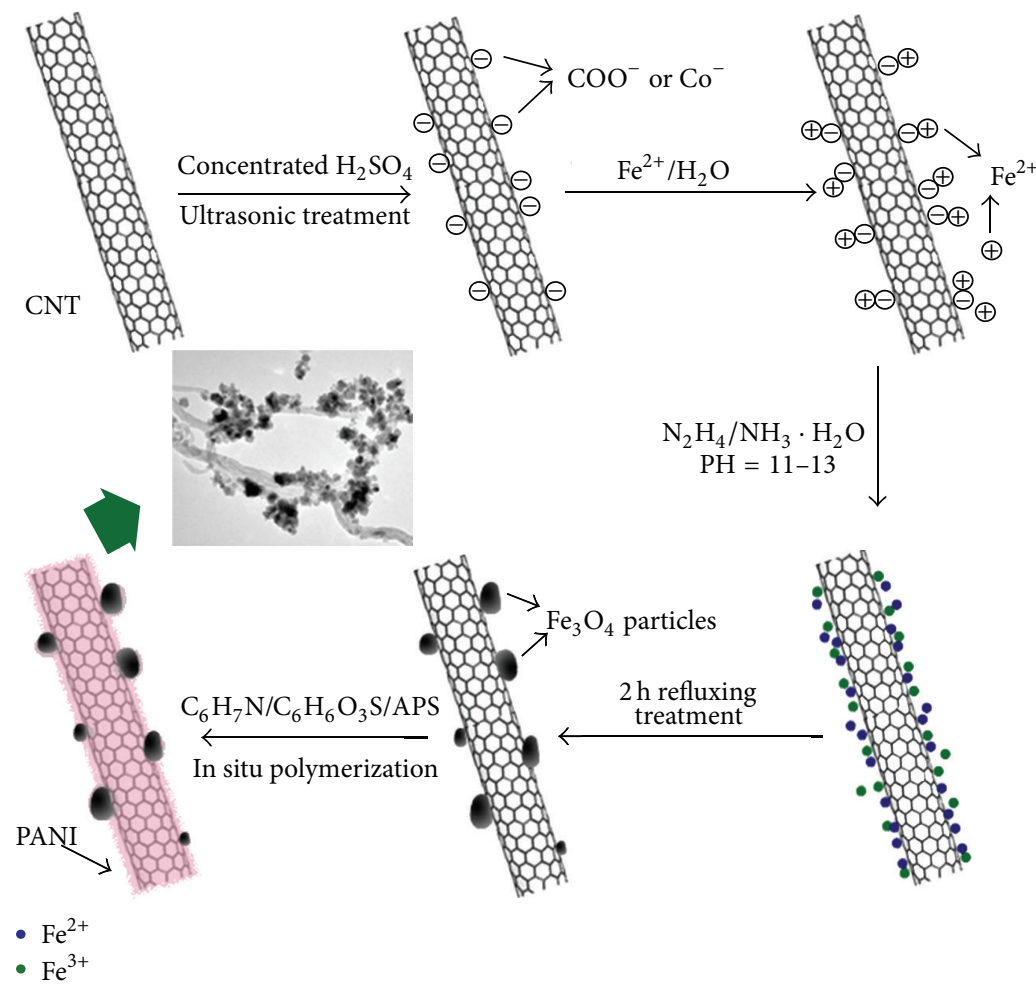

Figure 4: The possible formation process of the $\mathrm{CNTs} / \mathrm{Fe}_{3} \mathrm{O}_{4} / \mathrm{PANI}$ nanocomposites.

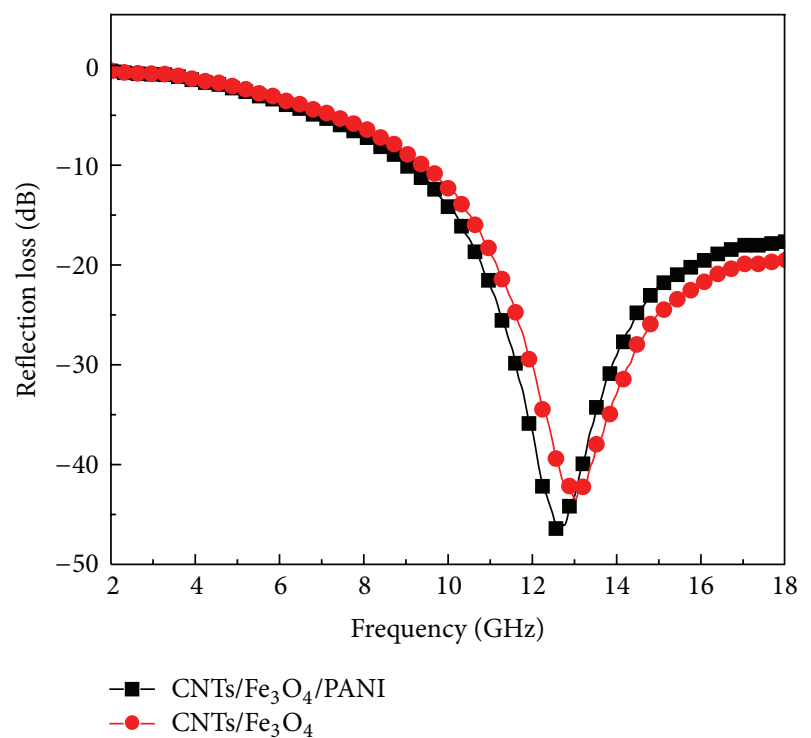

FIgURE 5: Microwave reflection loss curves of $\mathrm{CNTs} / \mathrm{Fe}_{3} \mathrm{O}_{4} / \mathrm{PANI}$ wax composites and $\mathrm{CNTs} / \mathrm{Fe}_{3} \mathrm{O}_{4}$ wax composites.

and the absorption peak increases to $33 \mathrm{~dB}$ at paraffin wax weight ratio of $15 \mathrm{wt} \%$ and then reaches the maximum value of $48 \mathrm{~dB}$ at the paraffin wax weight ratio of $20 \mathrm{wt} \%$. But with further increasing paraffin wax weight ratio, the waveabsorbing ability decreases. Also, it is clearly seen that the peak position moves to lower frequencies with increasing paraffin wax weight. In addition, we also explored the influence of absorber thickness on wave-absorbing performance by calculation. The absorber thickness $(d)$ was considered to be $1,1.5,2,2.5,3,3.5$, and $4 \mathrm{~mm}$, respectively. The evaluated reflection loss of $\mathrm{CNTs} / \mathrm{Fe}_{3} \mathrm{O}_{4} / \mathrm{PANI}$ composites coupled with different thicknesses is shown in Figure 6(b). It is obviously exhibited that the reflection loss peaks shift from higher to lower frequency as the thickness increases, associated with quarter-wavelength attenuation [29]. Furthermore, the $\mathrm{CNTs} / \mathrm{Fe}_{3} \mathrm{O}_{4} / \mathrm{PANI}$ composites demonstrate excellent microwave absorption performance with wide absorption bandwidth in an effective range of thickness. In the investigated region, the maximum reflection loss peak achieves up to $48 \mathrm{~dB}$ ( $2 \mathrm{~mm}$ in thickness). These results above are of importance since the absorption peak frequency ranges of the $\mathrm{CNTs} / \mathrm{Fe}_{3} \mathrm{O}_{4} / \mathrm{PANI}$ composites can be tuned easily by changing the wax weight ratio and absorber thickness, and thus a broadband and effective absorption design could be achieved using $\mathrm{CNTs} / \mathrm{Fe}_{3} \mathrm{O}_{4} / \mathrm{PANI}$ composite nanomaterials.

\section{Conclusions}

In summary, we have developed a simple method to synthesize the $\mathrm{CNTs} / \mathrm{Fe}_{3} \mathrm{O}_{4} / \mathrm{PANI}$ composite nanostructures. The $\mathrm{Fe}_{3} \mathrm{O}_{4}$ magnetic nanoparticles have the diameters of 3-5 nm. The $\mathrm{Fe}_{3} \mathrm{O}_{4}$ nanoparticles were strongly attached to the surface of CNTs by the action of PANI. The CNTs/ $\mathrm{Fe}_{3} \mathrm{O}_{4} / \mathrm{PANI}$ composites reveal super microwave absorption properties and possess a maximum reflection loss of $-48 \mathrm{~dB}$ at $12.9 \mathrm{GHz}$, 


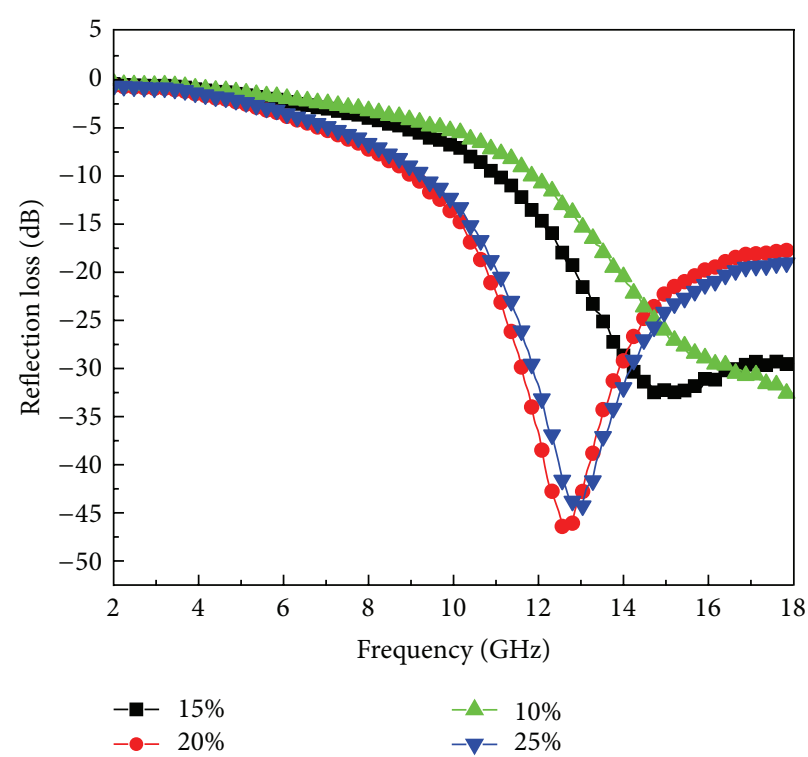

(a)

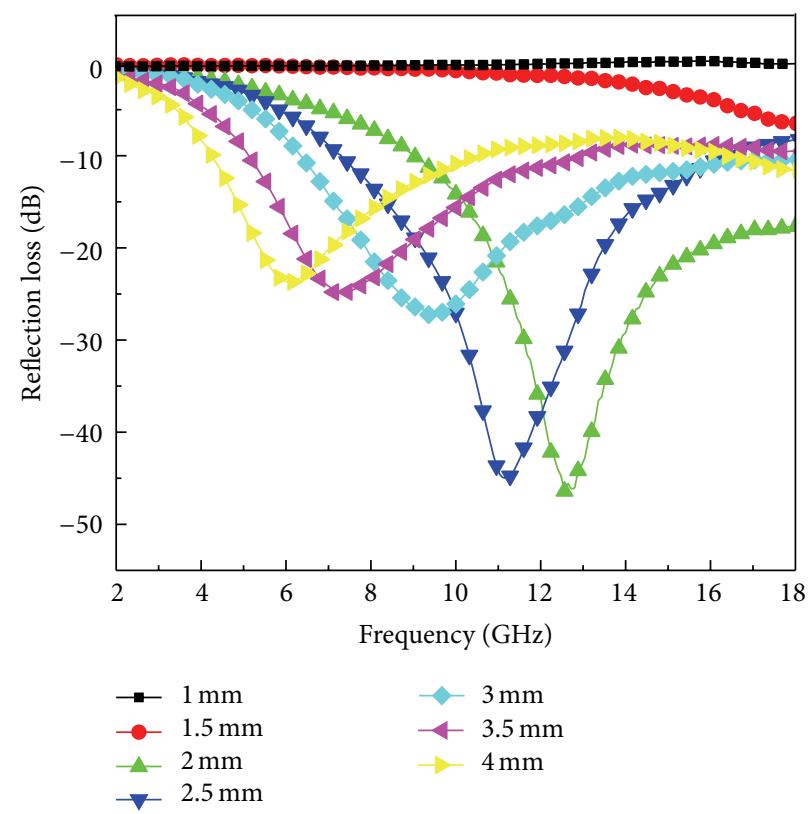

(b)

FIgure 6: Microwave reflection loss curves of $\mathrm{CNTs} / \mathrm{Fe}_{3} \mathrm{O}_{4} / \mathrm{PANI}$ wax composites with different paraffin wax weight ratio (a) and different thickness (b).

and the bandwidth below $-20 \mathrm{~dB}$ is more than $5 \mathrm{GHz}$, which is much higher than many CNT-based samples. In addition, the absorption peak frequency ranges of the $\mathrm{CNTs} / \mathrm{Fe}_{3} \mathrm{O}_{4} / \mathrm{PANI}$ composites can be tuned by changing the wax weight ratio and its thickness. All the results indicate that the $\mathrm{CNTs} / \mathrm{Fe}_{3} \mathrm{O}_{4} / \mathrm{PANI}$ composite nanomaterials may be attractive candidate materials for microwave absorption applications.

\section{Acknowledgment}

This work was supported by the National Science Foundation of China (Grant nos. 50972014, 51072024, and 51132002).

\section{References}

[1] C. Tong, Advanced Materials and Design for Electromagnetic Interference, Taylor \& Francis, Boca Raton, Fla, USA, 2008.

[2] J. Zhu, S. Wei, N. Haldolaarachchige, D. P. Young, and Z. Guo, "Electromagnetic field shielding polyurethane nanocomposites reinforced with core-shell Fe-silica nanoparticles," Journal of Physical Chemistry C, vol. 115, no. 31, pp. 15304-15310, 2011.

[3] H. Gu, Y. Huang, X. Zhang et al., "Magnetoresistive polyanilinemagnetite nanocomposites with negative dielectrical properties," Polymer, vol. 53, no. 3, pp. 801-809, 2012.

[4] X. Zhang, S. Y. Wei, N. Haldolaarachchige, and H. A. Colorado, "Magnetoresistive conductive polyaniline-barium titanate nanocomposites with negative permittivity," Journal of Physical Chemistry C, vol. 116, no. 29, pp. 15731-15740, 2012.

[5] H. Li, Y. Huang, G. Sun et al., "Directed growth and microwave absorption property of crossed $\mathrm{ZnO}$ netlike micro/nanostructures," Journal of Physical Chemistry C, vol. 114, no. 22, pp. 10088-10091, 2010.
[6] S. J. Yan, L. Zhen, C. Y. Xu, J. T. Jiang, W. Z. Shao, and J. K. Tang, "Synthesis, characterization and electromagnetic properties of $\mathrm{Fe}_{1-x} \mathrm{Co}_{x}$ alloy flower-like microparticles," Journal of Magnetism and Magnetic Materials, vol. 323, no. 5, pp. 515520, 2011.

[7] R. H. Baughman, A. A. Zakhidov, and W. A. De Heer, "Carbon nanotubes-the route toward applications," Science, vol. 297, no. 5582, pp. 787-792, 2002.

[8] Y. Shan, K. Chen, X. Yu, and L. Gao, "Preparation and characterization of biocompatible magnetic carbon nanotubes," Applied Surface Science, vol. 257, no. 2, pp. 362-366, 2010.

[9] L. Zhang, Q.-Q. Ni, T. Natsuki, and Y. Fu, "Carbon nanotubes/magnetite hybrids prepared by a facile synthesis process and their magnetic properties," Applied Surface Science, vol. 255, no. 20, pp. 8676-8681, 2009.

[10] R. Che, L.-M. Peng, X. Duan, Q. Chen, and X. Liang, "Microwave absorption enhancement and complex permittivity and permeability of Fe encapsulated within carbon nanotubes," Advanced Materials, vol. 16, no. 5, pp. 401-405, 2004.

[11] F. S. Wen, F. Zhang, and Z. Y. Liu, "Investigation on microwave absorption properties for multiwalled carbon nanotubes/Fe/Co/Ni nanopowders as lightweight absorbers," Journal of Physical Chemistry C, vol. 115, no. 29, pp. 14025-14030, 2011.

[12] X.-L. Shi, M.-S. Cao, J. Yuan, and X.-Y. Fang, "Dual nonlinear dielectric resonance and nesting microwave absorption peaks of hollow cobalt nanochains composites with negative permeability," Applied Physics Letters, vol. 95, no. 16, Article ID 163108, 2009.

[13] K. Jia, R. Zhao, J. Zhong, and X. Liu, "Preparation and microwave absorption properties of loose nanoscale $\mathrm{Fe}_{3} \mathrm{O}_{4}$ spheres," Journal of Magnetism and Magnetic Materials, vol. 322, no. 15, pp. 2167-2171, 2010. 
[14] S. B. Ni, X. L. Sun, X. H. Wang et al., "Low temperature synthesis of $\mathrm{Fe}_{3} \mathrm{O}_{4}$ micro-spheres and its microwave absorption properties," Materials Chemistry and Physics, vol. 124, no. 1, pp. 353-358, 2010.

[15] M. A. Correa-Duarte, M. Grzelczak, V. Salgueiriño-Maceira et al., "Alignment of carbon nanotubes under low magnetic fields through attachment of magnetic nanoparticles," Journal of Physical Chemistry B, vol. 109, no. 41, pp. 19060-19063, 2005.

[16] S. C. Youn, D.-H. Jung, Y. K. Ko, Y. W. Jin, J. M. Kim, and H.-T. Jung, "Vertical alignment of carbon nanotubes using the magneto-evaporation method," Journal of the American Chemical Society, vol. 131, no. 2, pp. 742-748, 2009.

[17] B. Jia, L. Gao, and J. Sun, "Self-assembly of magnetite beads along multiwalled carbon nanotubes via a simple hydrothermal process," Carbon, vol. 45, no. 7, pp. 1476-1481, 2007.

[18] B. Q. Yuan, L. M. Yu, L. M. Sheng, K. An, and X. L. Zhao, "Comparison of electromagnetic interference shielding properties between single-wall carbon nanotube and graphene sheet/polyaniline composites," Journal of Physics D, vol. 45, Article ID 235108, 2012.

[19] T. Fujii, F. M. F. De Groot, G. A. Sawatzky, F. C. Voogt, T. Hibma, and K. Okada, "In situ XPS analysis of various iron oxide films grown by $\mathrm{NO}_{2}$-assisted molecular-beam epitaxy," Physical Review B, vol. 59, no. 4, pp. 3195-3202, 1999.

[20] S. Y. Lian, Z. H. Kang, E. B. Wang, M. Jiang, C. Hu, and L. $\mathrm{Xu}$, "Convenient synthesis of single crystalline magnetic $\mathrm{Fe}_{3} \mathrm{O}_{4}$ nanorods," Solid State Communications, vol. 127, no. 9-10, pp. 605-608, 2003.

[21] W. Kim, K. Kawaguchi, N. Koshizaki, M. Sohma, and T. Matsumoto, "Fabrication and magnetoresistance of tunnel junctions using half-metallic $\mathrm{Fe}_{3} \mathrm{O}_{4}$," Journal of Applied Physics, vol. 93, no. 10, pp. 8032-8034, 2003.

[22] J. G. Deng, Y. X. Peng, C. L. He, X. Long, P. Li, and A. S. C. Chan, "Magnetic and conducting $\mathrm{Fe}_{3} \mathrm{O}_{4}$-polypyrrole nanoparticles with core-shell structure," Polymer International, vol. 52, no. 7, pp. 1182-1187, 2003.

[23] M. Amrithesh, S. Aravind, S. Jayalekshmi, and R. S. Jayasree, "Enhanced luminescence observed in polyanilinepolymethylmethacrylate composites," Journal of Alloys and Compounds, vol. 449, no. 1-2, pp. 176-179, 2008.

[24] M. G. Deng, B. C. Yang, and Y. D. Hu, "Polyaniline deposition to enhance the specific capacitance of carbon nanotubes for supercapacitors," Journal of Materials Science, vol. 40, no. 18, pp. 5021-5023, 2005

[25] R. Che, L.-M. Peng, X. Duan, Q. Chen, and X. Liang, "Microwave absorption enhancement and complex permittivity and permeability of Fe encapsulated within carbon nanotubes," Advanced Materials, vol. 16, no. 5, pp. 401-405, 2004.

[26] M.-S. Cao, W.-L. Song, Z.-L. Hou, B. Wen, and J. Yuan, “The effects of temperature and frequency on the dielectric properties, electromagnetic interference shielding and microwaveabsorption of short carbon fiber/silica composites," Carbon, vol. 48, no. 3, pp. 788-796, 2010.

[27] Z. J. Fan, G. H. Luo, Z. F. Zhang, L. Zhou, and F. Wei, "Electromagnetic and microwave absorbing properties of multi-walled carbon nanotubes/polymer composites," Materials Science and Engineering B, vol. 132, no. 1-2, pp. 85-89, 2006.

[28] Z. F. Liu, G. Bai, Y. Huang et al., "Microwave absorption of single-walled carbon nanotubes/soluble cross-linked polyurethane composites," Journal of Physical Chemistry C, vol. 111, no. 37, pp. 13696-13700, 2007.
[29] W.-L. Song, M.-S. Cao, B. Wen, Z.-L. Hou, J. Cheng, and J. Yuan, "Synthesis of zinc oxide particles coated multiwalled carbon nanotubes: Dielectric properties, electromagnetic interference shielding and microwave absorption," Materials Research Bulletin, vol. 47, no. 7, pp. 1747-1754, 2012. 

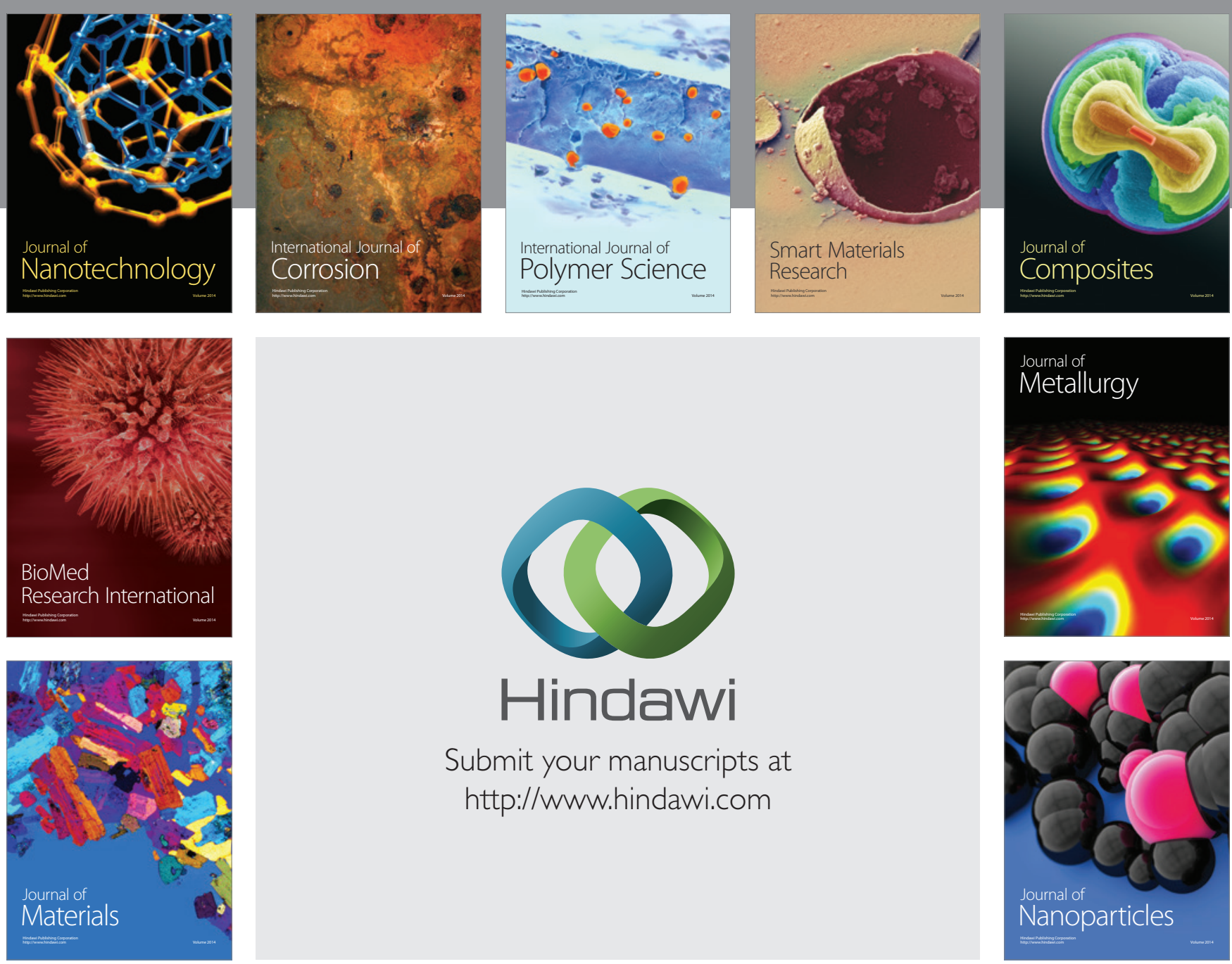

Submit your manuscripts at http://www.hindawi.com
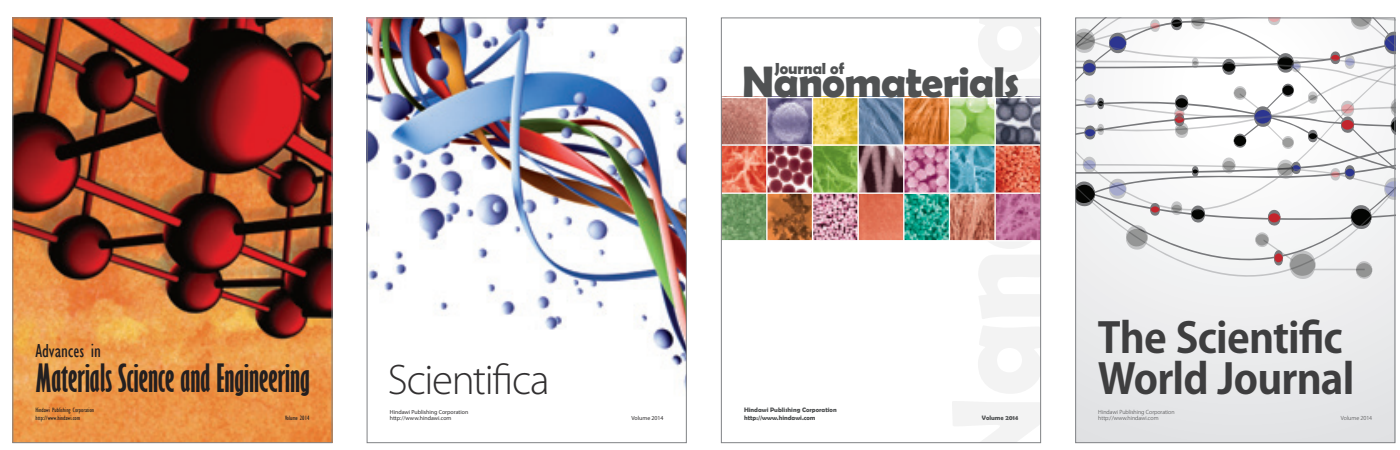

\section{The Scientific World Journal}
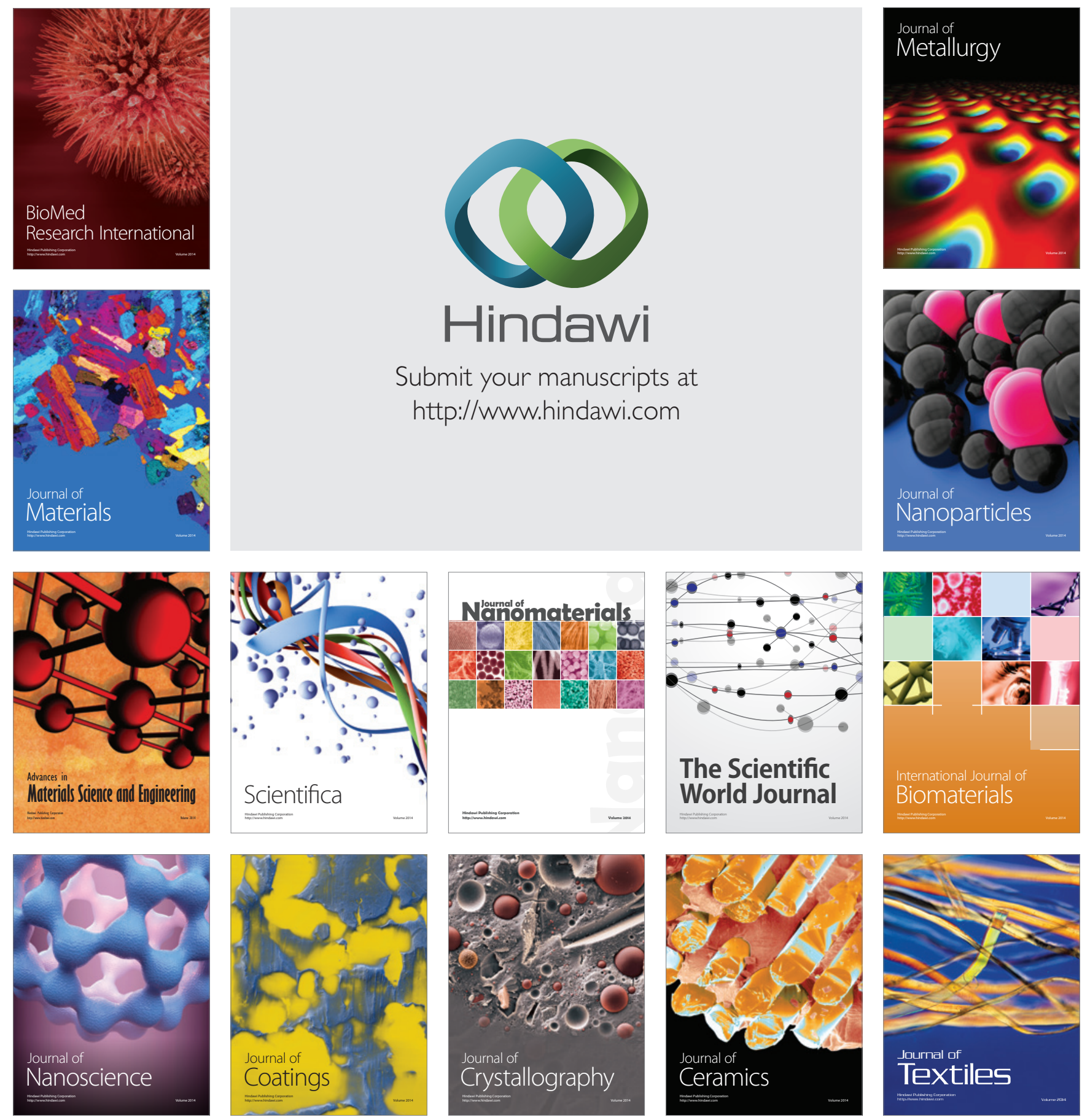